\title{
Gerakan Perempuan di Jawa (1912-1941)
}

\author{
Budi Sujati, Ilfa Harfiatul Haq \\ STKIP Pangeran Dharma Kusuma Indramayu \\ STKIP Pangeran Dharma Kusuma Indramayu \\ budisujati@gmail.com
}

\begin{abstract}
Gender issues in Indonesia can be seen from the aspect of space and time on the basis of culture that applies in various places and at certain times. At that time, the culture of Javanese culture in particular placed women as people who had narrower social rights than men in the conditions of Dutch colonialism. This study aims to trace the steps of the women's movement in Java during the National Movement. This study uses Historical Research Methods that go through stages: Heuristics, Criticism, Interpretation, and Historiography. The Women's Movement began its struggle by establishing schools, then accompanied by the establishment of organizations and in its development held congresses. Through educational facilities, of course, it will produce educated women who will be able to fight for their rights by expressing ideas and thoughts, both verbally and in writing.
\end{abstract}

Keywords : Java, Movement, Women.

Abstrak. Permasalahan Gender di Indonesia dapat dilihat dari aspek ruang dan waktu atas dasar kultur yang berlaku di berbagai tempat dan dalam waktu tertentu. Pada masa itu, kultur budaya Jawa khususnya menempatkan kaum perempuan sebagai kaum yang memiliki hak-hak sosial yang lebih sempit dibandingkan dengan kaum laki-laki di tengah kondisi penjajahan Belanda. Penelitian ini bertujuan untuk melacak jejak langkah gerakan perempuan di Jawa pada masa Pergerakan Nasional. Penelitian ini menggunakan Metode Penelitian Sejarah yang melalui tahapan: Heuristik, Kritik, Interpretasi, dan Historiografi. Gerakan Perempuan mulai melakukan perjuangannya dengan mendirikan sekolah-sekolah, lalu disertai dengan pendirian organisasi-organisasi dan pada perkembangannya menyelenggarakan kongres-kongres. Melalui sarana pendidikan tentunya akan menghasilkan perempuan-perempuan terdidik yang nantinya akan dapat memperjuangkan haknya dengan menuangkan gagasan dan pemikiran, baik secara lisan maupun tulisan.

Kata Kunci : Java, Gerakan, Perempuan.

\section{PENDAHULUAN}

Gerakan Perempuan tidak pernah mengalami keseragaman dan kesetaraan di dunia ini. Antara satu negara dan satu budaya dengan negara dan budaya lain memiliki pola yang berbeda, bahkan ambivalen. Feminisme sebagai sebuah paham dalam perjuangan pergerakan perempuan juga 
mengalami interpretasi dan penekanan yang berbeda di berbagai negara termasuk di Indonesia (Hanafi, 2015, h. 276).

Persoalan gender di Indonesia dapat dilihat dari aspek ruang dan waktu atas dasar kultur yang berlaku di berbagai tempat dan dalam waktu tertentu. Pada masa itu, kultur budaya masyarakat Indonesia di Jawa khususnya menempatkan kaum perempuan sebagai kaum yang memiliki hakhak sosial yang lebih sempit dibandingkan dengan kaum laki-laki. Kaum perempuan sebagai sosok yang ditempatkan sebagai kelompok yang dibatasi ruang geraknya. Saat ini ada istilah "pingitan," yang berarti perempuan harus tinggal di dalam rumah dan tidak boleh bekerja di luar rumah, bahkan tidak diberikan hak untuk mengenyam pendidikan (Setiadi, 2011, h. 876).

Kultur pada masyarakat Jawa juga menempatkan kaum perempuan terkait pembagian hak waris keluarga dengan rumus 'segendongan sepikul” atau satu banding setengah. Bahkan tata nilai ini seolah-olah dijustifikasi dalam ajaran agama Islam yang menempatkan kaum perempuan tidak dapat menduduki jabatan sebagai pemimpin, tetapi masalah aturan ini masih bersifat multitafsir. Selain itu adanya hak-hak kaum laki-laki untuk melakukan poligami, sedangkan bagi kaum perempuan menjadi sebuah larangan keras untuk melakukan poliandri. Kenyataan ini tentunya menimbulkan sikap pro dan kontra, di mana satu pihak menganggap gejala ini sebagai bentuk ketidakadilan, tetapi di pihak lain justru menganggap hal ini sebagai langkah untuk memuliakan perempuan (Setiadi, 2011, h. 877-878).

Padahal Islam sesungguhnya lahir dengan suatu konsepsi hubungan manusia yang berdasarkan keadilan (justice) atas kedudukan laki-laki dan perempuan. Inti dari gerakan feminisme adalah memperjuangkan keadilan gender sebagai salah satu bagian dari keadilan sosial. Agama Islam yang berpedoman kepada al-Qur'an dan Hadits merupakan sumber nilai dan pendukung terbaik dalam perjuangan menjamin hak-hak perempuan. Kaum feminisme dari kalangan Islam tidak menekankan kekuatannya pada 
perempuan dengan mengabaikan potensi laki-laki ataupun menjatuhkannya. Tetapi perempuan dan laki-laki sebenarnya diciptakan sebagai mitra yang dapat saling melengkapi satu sama lain serta hidup berdampingan secara harmonis dalam menegakkan nilai-nilai keadilan dan kebenaran (Jones, Boutillier, 2016, h. 25). Berangkat dari sinilah tulisan ini akan menjelaskan Gerakan perempuan di Jawa 1912-1941.

Pada perkembangan penulisan sejarah Indonesia, tema Sejarah gerakan Wanita dapat dikatakan ketinggalan dari ilmu-ilmu sosial lainnya seperti sosiologi dalam penelitian wanita, sekalipun "Women Studies" juga belum mempunyai kedudukan tersendiri dalam ilmu-ilmu sosial di negeri ini. Meskipun demikian, baik ilmu-ilmu sosial di Indonesia maupun sejarah mempunyai kekurangan masing-masing. Sosiologi, Demografi, dan Ekonomi paling-paling membicarakan wanita sebagai penyumbang, seperti Nampak dalam judul-judul karangan untuk seminar, penelitian, dan kebijakan sosial.

Menurut Kuntowijoyo (2003, h. 114), peranan wanita dalam gerakan sejarah rupanya tidak pernah berdiri sendiri. Memang, kita tahu dunia ini terdiri dari separuh laki-laki dan separuh perempuan, tetapi dengan kata "gerakan dan peranan" kita mengartikannya secara konotatif bahwa wanita hanyalah penyumbang, sedangkan dunia ini hanyalah dunia laki-laki. Disiplin sejarah sebenarnya mempunyai keunggulan dari ilmu sosial lainnya, sekalipun ketinggalan dalam kuantitas dan kesadaran pentingnya wanita. Sejarah sudah menganggap bahwa wanita adalah pribadi yang bisa berdiri sendiri, sebagaimana bisa dibuktikan oleh banyaknya buku-buku yang ditulis tentang tokoh-tokoh wanita. (Kuntowijoyo, 2003, h. 114)

Salah satunya yang membahas mengenai sejarah gerakan wanita di antaranya Kongres Wanita Indonesia, Sejarah Setengah Abad Wanita Indonesia yang sudah mulai dimunculkan di permukaan. Gerakan-gerakan wanita tersebut di Indonesia dipelopori di Jawa karena pada waktu itu Jawa merupakan pusat pergerakan nasional di Indonesia walaupun ada di beberapa 
daerah seperti di Sumatera, Sulawesi dan Kalimantan sudah mewakili entitas tersebut. Oleh karenanya, Tema Gerakan Perempuan di Jawa pada 1912-1941 menjadi fokus utama dalam metode penulisan ini yang coba dideskripsikan dengan interpretatif dan komprehensif.

\section{HASIL DAN PEMBAHASAN}

\section{Awal Kemunculan Gerakan Perempuan di Jawa}

Setelah Era kolonialisme dan imperialisme bangsa-bangsa barat sudah mulai luntur di abad ke-19, digantikan dengan zaman pergerakan nasional di berbagai belahan dunia khususnya di Indonesia. Salah satunya dalam hal ini adalah gerakan perempuan di Indonesia. Penerapan Politik Etis (Ethische Politiek) atau yang dikenal dengan Politik Balas Budi oleh pemerintah kolonial Belanda pada periode itu, terutama melalui pembangunan lembagalembaga pendidikan modern, telah menciptakan satu masyarakat baru yang sangat akrab dengan unsur-unsur modernitas. Bersamaan dengan itu, pertumbuhan sejumlah kota di beberapa wilayah di Indonesia, yang terjadi menyusul proses urbanisasi, telah menciptakan ruang baru yang menyediakan masyarakat melalui sejumlah perangkat untuk hidup di tengah suasana modern yang maju. Dalam kondisi yang demikian, masyarat kelas menengah di perkotaan kemudian tampil dengan terma-terma yang baru mengekspresikan hasrat kemajuan. Hal demikian itulah yang terjadi dalam gerakan perempuan di Indonesia. Mereka menjadi bagian dari gerakan bangsa Indonesia secara umum yang menghendaki adanya kemajuan. Oleh karena itu, reformulasi atas nilai-nilai budaya lama yang sudah mapan, menjadi sesuatu yang tak terelakkan dan sebuah upaya reformulasi yang berangkat dari argumen baru yang berbasis pada ideologi kemajuan. (Burhanudin, Fathurrahman, 2004, h. 2)

Organisasi-organisasi pergerakan perempuan ini telah membawa perkembangan di dalam sejarah feminisme, yang kemudian dibagi ke dalam dua gelombang. Gelombang pertama yaitu yang berlangsung sekitar tahun 
1860-1920, sedangkan gelombang kedua yang berlangsung sekitar tahun 1960-1970an. Paham feminisme ini berkembang pesat di negara-negara Barat dan lama kelamaan paham ini juga menyebar ke negara-negara lain, termasuk Indonesia dan khususnya pulau Jawa (Noer, 1980, h. 125).

Salah satunya adalah pergerakan Perempuan di Indonesia memiliki perbedaan dengan feminisme di Barat. Feminisme di dunia Barat bertujuan untuk melawan usaha para lelaki, dan agar dapat mencapai kepentingankepentingan yang berkaitan dengan hak-hak perempuan. Sedangkan pergerakan perempuan di Indonesia pada tahap awal lebih mengarah kepada usaha-usaha untuk memajukan perempuan di bidang pendidikan, politik dan sosial; sebagai usaha untuk melawan penjajahan bangsa Belanda dengan kesadaran nasional untuk memberikan kesempatan ruang bagi rakyat Indonesia mengelola segala sumber daya yang ada di bumi pertiwi (Noer, 1980, h. 125).

Karenanya, konsep atau ideologi pergerakan perempuan di Indonesia tidak harus sepenuhnya mengadopsi konsep-konsep Barat, khususnya yang berkenaan dengan emansipasi. Di dalam ajaran Islam, yang dijelaskan melalui kitab suci al-qur'an maupun perkataan nabi (hadits) sudah mengatur hubungan manusia dengan sang maha pencipta (vertikal) dan mengatur hubungan manusia dengan manusia (horizontal), sangat kaya akan prinsipprinsip kesetaraan, keadilan, kebebasan, serta pesan-pesan moral mengenai pentingnya pemuliaan terhadap harkat dan martabat manusia. Kesemuanya itu pada esensinya sangat akomodif terhadap gagasan persamaan kedudukan (emansipasi). ( Ida, et.al, 2018, h. 152)

\section{Perkembangan Gerakan Organisasi Perempuan di Jawa (1912-1941)}

Pada awal abad ke-20, gerakan perempuan di Indonesia tidak terlepas dari gerakan sosial internasional yang bertujuan emansipasi, nasionalisme, serta kemerdekaan dari kekangan kolonialisme. Para perempuan dalam 
organisasi perempuan berjuang bersama dengan gerakan nasionalisme untuk menghilangkan ketidak adilan dalam sistem kolonial (Noer, 1980, h. 152).

Pada masa awal pergerakan Indonesia, pergerakan perempuan lebih terfokus pada perjuangan untuk mempertinggi kedudukan sosial. Pergerakan perempuan ini tidak hanya menentang ketidak adilan sosial dari sistem kolonial saja, tetapi juga masalah perkawinan paksa dan praktek poligami. Problem itulah yang mengawali pertumbuhan organissi perempuan pada awal abad ke-20. (Struers, 2008, h. 12).

Dimulainya gerakan perempuan merupakan atas inisiatif perorangan dan tidak dalam susunan perkumpulan ataupun suatu organisasi. Hal ini diperlihatkan di beberapa di daerah nusantara, diantaranya: R.A. Kartini di Jepara, Dewi Sartika di Bandung, Tjut Nyak Dien di Aceh dan tokoh-tokoh perempuan lainnya (Lapian, et.al, 2011, h. 367). Salah satunya adalah perlawanan Tjut Nyak Dien terhadap kolonialisme dan imprealisme di Serambi Mekah (Aceh), dan kritikan Kartini terhadap poligami di Indonesia dengan memperjuangkan hak-hak perempuan, serta dan Keutamaan Istri yang digagas oleh Dewi Sartika di Bandung (1910) berdiri dengan tujuan mengadakan rumah-rumah sekolah untuk perempuan, antara lain di Tasikmalaya (1913), Sumedang (1916), Cianjur (1916), Ciamis (1917), dan Sukabumi (1918). Di samping itu juga berdiri sekolah-sekolah Kartini di Jakarta (1913), Madiun (1914), Malang dan Cirebon (1916), Pekalongan (1917), Indramayu (1918), Surabaya, Rembang, serta kota lainnya. Selain itu juga mulai muncul perkumpulan kaum ibu untuk kegiatan keterampilan, seperti memasak, menjahit, merenda, dan pemeliharaan anak. Mereka berkumpul dalam perkumpulan Pawiyatan Wanito (Magelang 1915), Wanito Hadi (Jepara 1915), ataupun Wanito Susilo (Pemalang 1918) (Lapian, et.al, 2011, h. 367).

Adapun Organisasi formal perempuan yang pertama kali berdiri adalah Putri Mardika, yang didirikan di Jakarta pada 1912. Organisasi ini 
memperjuangkan pendidikan di kalangan perempuan, dengan tujuan mendorong kaum wanita memiliki jiwa keberanian di ruang publik, dan mengangkat harkat dan martabat perempuan untuk mendapat kedudukan yang sama dengan laki-laki. Sekitar tahun 1913-1915 berdiri berbagai organisasi perempuan, terutama di Jawa. Fokus perhatian organisasiorganisasi ini adalah dengan mendobrak penjara rumah tangga yang telah membuat mereka terkurung bagai burung, dan memajukan rakyat jawa secara menyeluruh (Adam, 2007, h. 10).

Karakteristik gerakan wanita di Jawa pada masa awal pada umumnya bergerak untuk perbaikan taraf kedudukan perempuan dalam hidup rumah tangga, memperluas kecakapan sebagai ibu dan dan memperbaiki kualitas pendidikan perempuan yang pada waktu itu dianggap termarjinalkan. Gerak maju perempuan ini dilakukan dengan tidak merongrong kedudukan kaum lelaki, tetapi untuk melawan penjajah yang yang melakukan motif politis balas budi (politics ethics).

Salah satu program politik etis yaitu dalam bidang pendidikan meningkatnya pendidikan di kalangan masyarakat, pada 1920-an perkumpulan perempuan pun bertambah. Dalam organisasi Sarekat Islam misalnya, terdapat organisasi Perempuan Sosialis Sarekat Rakyat, bersifat sayap merah, yang sebagian anggotanya bergabung dengan PKI. Terdapat beberapa tokoh perempuan yang sangat gigih di antara anggotanya, seperti Raden Sukaesih dan Munapsiah (ANRI, 1981, h. 3). Pada saat diselenggarakannya Congres PKI di Jakarta pada 7-10 Juni 1924, kedua tokoh ini berbicara di depan Congres bahwa perempuan yang tidak berjuang untuk hak-hak mereka pasti akan disisihkan oleh laki-laki dan kapitalis. Congres PKI tersebut menyediakan satu hari khusus untuk membicarakan gerakan wanita komunis. Akhir pemberontakan PKI (1927), Sukaesih dipenjara dan dikirim ke kamp Bogen Digul (Nordholt, Purwanto, 2013, h. 126). 
Organisasi perempuan berdasarkan keagamaan yang mempunyai peranan penting adalah Aisiyah. Aisiyah dimulai sejak KH Ahmad Dahlan mendirikan Muhammadiyah, yang menyadari perlunya bantuan perempuan dalam menyelenggarakan sejumlah kursus mengenai perintah agama. Pada tahun 1914, perempuan Muhammadiyah dihimpun dalam perkumpulan bernama Sopo Treno, dan baru pada 1917 berubah nama menjadi Aisiyah, dengan Nyai Ahmad Dahlan sebagai ketuanya. Pada tahun 1929, Aisiyah telah mempunyai 5.000 anggota, tersebar dalam 47 cabang dan 50 ranting, dan mempunyai 32 rumah sekolah perempuan dengan 75 guru putri (Lapian, 2011, h. 368).

Selain perkumpulan dari perempuan Muslim, perempuan Katolik juga mendirikan perkumpulan dengan nama Wanito Katolik. Sebelumnya pernah ada perkumpulan De Katholieke Vrowwen Bond yang sebagian anggotanya adalah perempuan bangsa Belanda yang beragama Katolik. Wanito Katolik terbentuk berkat usaha Raden Ayu Maria Sulastri Darmoseputro, dan berhasil menyusun kepengurusannya dengan ketua Raden Ayu Catharina Harjodiningrat.

Ada pula perkumpulan perempuan di daerah-daerah seperti Ina Tuni di Ambon yang membantu aksi Sarekat Ambon, Wanito Utomo, dan Wanito Muljo yang berdiri di Yogyakarta, dan Puteri Budi Sejati yang berdiri di Surabaya. Perkumpulan pelajar puteri juga mengadakan organisasi pemudipemudi pelajar, di antaranya Puteri Indonesia, yang merupakan bagian dari Pemuda Indonesia, Jong Islamicten Bond Dames Afdeling (JIBDA), Jong Java bagian gadis, dan organisasi Wanita Taman Siswa (Lapian, 2011, h. 369).

Gagasan-gagasan ke-Indonesia-an yang semakin kuat telah mengantarkan organisasi perempuan dalam Kongres Perempuan Indonesia I di Yogyakarta pada tanggal 22-25 Desember 1928. Kongres ini diprakarsai oleh tujuh organisasi perempuan yaitu Wanita Aisyiah, Wanito Utomo, Jong Islamicten Bond Domes Afdeeling bagian perempuan (JIBDA) dan Nahdlatul 
Ulama Musimat (NUM). Kongres ini bertujuan mempersatukan cita-cita dan usaha untuk memajukan perempuan Indonesia dan mengadakan gabungan antara perkumpulan perempuan (Lapian, 2011, h. 369).

Menurut Lapian (2011) Kongres perempuan pertama yang dihadiri hampir 30 organisasi perempuan dari seluruh Jawa dan Sumatera ini memiliki susunan kepanitiaan kongres sebagai berikut:

Ketua : R.A. Sukonto (Wanito Utomo)

Wakil Ketua : Siti Munjiah (Aisyiah)

Sekretaris I : Siti Sukaptinah (JIBDA)

Sekretaris II : Siti Sunaryati (Puteri Indonesia)

Bendahara : R.A. Harjodiningrat (Wanita Katolik)

Bendahara II : R.A. Sujatin (Puteri Indonesia)

Anggotanya antara lain Nyi Hadjar Dewantara, (Wanita Taman Siswa), Driyowongso (Wanita PSII), Muridan Noto (Wanita PSII), Ummi Salamah (Wanita PSII), Johanah (Aisyiah), Badiah Muryati (JIBDA), Hajinah (Aisyiah), Ismudiyati (Wanito Utomo), dan R.A. Mursandi (Wanita Katolik).

Berdasarkan informasi di atas, biografi dari 22 perempuan yang menonjol keterlibatannya dalam penyelenggaraan kongres tahun 1928 itu mengungkapkan beberapa data penting terkait mereka dilihat dari keterlibatannya dalam kelompok. Kebanyakan dari mereka berumur dua puluhan lebih sedikit, 14 orang sudah menikah, dan sisanya masih lajang (kebanyakan guru), dan ada beberapa berstatus janda, cerai nikah atau cerai mati. Hampir semua dari mereka berpendidikan sangat baik, bahkan banyak di antaranya memiliki pendidikan menengah dan sebagian memiliki pelatihan sebagai guru. Hanya ada dua orang yang tidak sempat mengenyam pendidikan formal. Bahkan mereka yang berpendidikan Islam, pernah mengenyam pendidikan modern. Kebanyakan dari mereka memiliki pengalaman mencari nafkah sendiri, baik sebagai guru, pedagang, maupun sebagai direktur asrama atau rumah yatim. Latar belakang sosialnya ada 
delapan orang dari kalangan priyayi, sedang lainnya dari kalangan keagamaan, dan ada seorang yang berasal dari kalangan keluarga miskin yang hidup sulit sebagai pedagang kecil yaitu Marakati Drijowongso (Blackburn, 2007, h. 16).

Jika ditinjau dari para pesertanya, diketahui bahwa kebanyakan dari mereka adalah perempuan-perempuan muda yang berasal dari keluarga Jawa yang tergolong menengah ke atas dan pernah menikmati pendidikan modern. Mereka mewakili kelompok Katolik dan Islam di Indonesia. Paling tidak dua orang beragama Katolik, sedangkan sisanya beragama Islam, dan lima orang di antaranya memiliki hubungan erat dengan kalangan keagamaan

Susan Blackburn (2007) menginformasikan dalam tulisannya, terdapat beberapa uraian tertulis tentang kongres yang mencakup 15 pembicaraan dengan judul pidatonya sebagai berikut:

1. R. A. Soedirman (Putri Budi Sejati, Surabaya): Pergerakan perempuan, Perkawinan, Perceraian.

2. Sitti Moendjijah (Aisyiyah, Yogyakarta): Derajat Perempuan

3. Moegaroemah (Putri Indonesia): Perkawinan Anak-anak

4. R.A Sitti Soendari Darmobroto (Putri Indonesia): Kewajiban dan Citacita Putri Indonesia

5. Tien Sastrowirjo: Bagaimanakah Jalan Kaum Perempuan Sekarang dan Nanti?

6. R.A. Soekonto (Wanito Utomo): Kewajiban Perempuan di dalam Rumah Tangga

7. Djami (Darmo Laksmi): Ibu

8. Siti ahra Goenawan (Rukun Wanodiyo): Salah satu kewajiban perempuan

9. Djojoadigoeno (Wanito Utomo): Kedudukan Perempuan dalam Kehidupan

10. Titi Sastroamidjojo: Keadaan Perempuan di Eropa 
11. Siti Marjam (Jong Java): Mengenai kebutuhan akan tenaga perempuan dalam pekerjaan sosial

12. Soetojo-Nimpoeno (Wanita Sejati, Bandung): Gambaran Perempuan dalam Rumah Tangga

13. Pidato tanpa judul oleh utusan tanpa nama dari Wanito Mulyo, Yogyakarta

14. Sitti Hajinah (Aisjijah): Persatuan Manusia

15. Nyi Hadjar Dewantoro (Wanita Taman Siswa): Adab Perempuan.

Hal menarik dari pidato-pidato dalam kongres tersebut bukan hanya bahwa isinya yang berbeda-beda, namun juga karena adanya aneka ragam gaya. Masing-masing pembicara itu punya latar belakangnya sendiri, tradisi icara yang berlainan dan memiliki tingkatan yang berbeda-beda dalam pengalaman berbicara di depan umum.

Adapun hasil suatu yang keputusan dari Kongres Perempuan I adalah:

1. Mendirikan badan pemufakatan dengan nama Perserikatan Perkumpulan Perempuan Indonesia (PPPI);

2. Mendirikan studiefonds untuk anak-anak perempuan yang tidak mampu membayar biaya sekolah dan berusaha memajukan kepanduan putri;

3. Mencegah pernikahan di bawah umur (Anshory, 2010, h. 120).

Hal yang menarik dalam kongres tersebut terdapat beberapa kritik dari beberapa anggota yang hadir salah satunya perwakilan dari Muhammadiyah dalam organisasi perempuannnya Aisyiyah. Yaitu yang dilontarkan oleh Siti Munjiah menyampaikan kritik terhadap tingginya perceraian yang diakibatkan nikah secara paksa. Selain hal itu, mode pakaian juga tidak luput dari kritiknya. Menurutnya, model pakaian yang bergantiganti terus dan tidak menutup aurat harus dicegah agar tidak merasuki putriputri Indonesia. Selain itu dengan masuknya budaya barat dikhawatirkan akan 
merusak budaya bangsa Indonesia, sehingga tidak semua pengetahuan barat dapat diambil tetapi tentunya harus disaring (filter) (Lapian, 2011, h. 369).

Pada perkembangan selanjutnya, diadakanlah kongres Permufakatan Perikatan Perempuan Indonesia (PPPI), 28-31 Desember 1929 di Jakarta, membahas tentang kewajiban perempuan dalam kehidupan sosial, ekonomi, pernikahan, dan keluarga, poligami, nikah paksa, dan pernikahan di bawah umur. Kongres tersebut disepakati telah terjadinnya penggabungan beberapa organisasi sehingga nama PPPI diubah menjadi Perikatan Perhimpunan Isteri Indonesia (PPII) agar lebih jelas bahwa organisasi tersebut bukanlah merupakan fusi, melainkan gabungan perkumpulan (federasi). Tujuan organisasi mengadakan hubungan di antara perkumpulan-perkumpulan perempuan adalah untuk memperbaiki nasib dan derajat perempuan Indonesia dan tidak mencampuri politik dan agama. Selain itu diberikan mosi kepada pemerintah untuk melarang pergundikan. Dalam kongres ini disepakati untuk menerbitkan surat kabar Isteri yang terbit di Jakarta. Selain itu juga didirikan stadiefonds PPII dengan nama Seri Derma.

Berbeda dengan kegiatan PPII, para perempuan Indonesia mengadakan Kongres Perempuan Indonesia II pada 20-24 Juli 1935 di Jakarta. Dalam kongres tersebut dapat diambil beberapa keputusan, yaitu mendirikan badan penyelidikan perburuhan perempuan yang harus mengamati pekerjaan perempuan Indonesia dan menggalang tiap-tiap perkumpulan untuk bergabung dalam memberantas buta aksara. Dasar-dasar kongres adalah perasaan kebangsaan, pekerjaan sosial, dan kenetralan terhadap agama. Kongres ini juga memutuskan bahwa Kongres Perempuan Indonesia akan dijadikan satu badan tetap dan berkumpul secara berkala. Undangan untuk berkumpul itu dikelola oleh Badan Kongres Perempuan. Akibat dari berdirinya badan ini, PPII melalui konferensinya pada bulan September 1935 resmi dibubarkan. Semua kekayaan diserahkan kepada Kongres Perempuan Indonesia (Lapian, 2011, h. 372). 
Selanjutnya Kongres Perempuan Indonesia ke-3 yang dilaksanakan pada bulan Juni 1938 di Bandung membahas permasalahan hak-hak politik kaum perempuan . Pada tahun 1938, pemerintah mengadakan peraturan tentang pemilihan anggota badan perwakilan. Akan tetapi melalui peraturan ini kaum wanita masih belum diberi kesempatan untuk turut memilih. Dalam tahun 1938 mulai terpilih anggota dewan kota yang berasal dari kalangan perempuan, seperti Ny. Emma Puradireja (Bandung), Ny. Sunarjo Mangunpuspito (Semarang), Ny. Sudirman (Surabaya), dan N. Umijati (Cirebon). Kongres ini juga memutuskan untuk meminta agar perempuan diberi kesempatan memilih dan dipilih secara luas. Istimewanya dalam kongres ke-3 ini juga diputuskan bahwa tanggal 22 Desember ditetapkan sebagai Hari Ibu yang diperingati setiap tahun dan diharapakan menambah kesadaran kaum perempuan Indonesia selurhnya akan kewajibannya sebagai "Ibu bangsa". Dalam kongres ke-3 ini pun Komite Perlindungan Kaum Perempuan dan Anak-anak Indonesia (KPKPAI) diubah nama menjadi Badan Perlindungan Perempuan Indonesia dalam Perkawinan (BPPIP) yang tugasnya meneruskan biro konsultasi dan mengumpulkan bahan-bahan untuk menyusun suatu rancangan undang-undang pernikahan bagi umat Islam (Lapian, 2011, h. 372).

Perhelatan Kongres Perempuan Indonesia ke-4 dilangsungkan pada bulan Juli 1941 di Semarang. Membahas masalah hak memilih dan dipilih masih menjadi tuntutan utama kaum perempuan, selain untuk mendukung GAPI dan melakukan tuntutan Indonesia berparlemen. Kongres ini menyetujui diadakannya pelajaran Bahasa Indonesia di sekolah-sekolah menengah dan Perguruan Tinggi. Selain itu juga dibuat 4 badan kerja yaitu untuk memberantas buta huruf, menyelidiki soal kerja perempuan Indonesia, mengurus soal pernikahan menurut hukum Islam, dan menangani perbaikan ekonomi kaum perempuan (Lapian, 2011, h. 373). 


\section{Dampak Positif dan Negatif dari Gerakan Perempuan}

Dalam setiap terjadinya peristiwa, apalagi jika berkaitan dengan adanya pergerakan yang kemudian akan membawa kepada perubahan, maka harus siap dihadapkan dengan segala dampaknya. Pergerakan di sini datang dari kaum perempuan yang ingin memperjuangkan haknya dan menuntut keadilan, sampai kemudian terjadi perubahan sesuai dengan yang diharapkan. Dari perubahan ini maka akan dapat dilihat dampaknya yang tidak terlepas dari baik atau tidaknya, yaitu sebagai berikut:

\section{Dampak Positif}

Dari gerakan perempuan ini mendatangkan dampak baik berupa peningkatan jenjang pendidikan perempuan yang disertai dengan meningkatnya taraf hidup perempuan. Selain itu, perempuan juga dapat turut serta ambil peran dengan mengisi posisi-posisi penting dalam sebuah organisasi, badan, lembaga, ataupun instansi terkait.

Adanya persamaan hak dan kewajiban di dalam kegiatan rumah tangga, walaupun dalam Islam peran perempuan dibatasi namun perempuan sangat dihargai dan dimuliakan. Seperti keutamaan seorang ibu yang mendapat strata tertinggi dalam derajat keutamaan surga bagi anaknya yang beriman (surga berada dibawah telapak kaki ibu).

\section{Dampak Negatif}

Dari gerakan perempuan ini mendatangkan dampak tidak baik berupa penurunan kesadaran akan fitrahnya sebagai perempuan dan kurang menganggap fitrahnya itu sebagai sesuatu yang bernilai ibadah.

Akan lebih baik lagi jika perempuan bisa menjalankan kedua perannya secara bersamaan dengan baik. Pertama, selaku pengurus rumah tangga yaitu sebagai ibu yang menjadi pendidik utama bagi anaknya dan pendamping bagi suaminya. Kedua, selaku warga negara yang mempunyai hak untuk turut serta berkiprah demi kemajuan bangsa. Seorang ibu memiliki andil yang besar dalam pembangunan suatu bangsa, yaitu menyiapkan sumber daya manusia 
yang berpotensi. Maka perlu untuk menjadi perempuan yang cerdas dan beretika, sehingga nantinya akan mencetak generasi penerus bangsa yang cemerlang.

\section{PENUTUP}

Berdasarkan penelitian yang telah penulis lakukan dengan mengkaji berbagai sumber yang bersangkutan maka didapat beberapa kesimpulan, yaitu sebagai berikut:

1. Pergerakan perempuan di Indonesia pada tahap awal lebih mengarah kepada usaha-usaha untuk memajukan perempuan di bidang pendidikan, sosial, dan politik; sebagai usaha untuk melawan penjajahan bangsa Belanda dengan kesadaran nasional untuk bersatu serta meraih kemerdekaan yang hakiki.

2. Perjuangan Gerakan Perempuan tidak terlepas dari peran tokoh-tokoh perempuan yang mendirikan sekolah-sekolah, lalu disertai dengan pendirian organisasi-organisasi pergerakan nasional, dan sampai kemudian berkembang dengan diselenggarakannya kongres-kongres. Melalui sarana pendidikan tentunya akan menghasilkan perempuanperempuan terdidik yang nantinya akan dapat memperjuangkan haknya dengan menuangkan gagasan dan pemikiran, baik secara lisan maupun tulisan.

3. Dari gerakan perempuan ini kemudian membawa dampak positif dan negatif. Dampak positifnya yaitu berupa peningkatan jenjang pendidikan yang disertai dengan meningkatnya taraf hidup perempuan. Sedangkan dampak negatifnya berupa penurunan kesadaran akan fitrahnya sebagai perempuan dan kurang menganggap fitrahnya itu bernilai ibadah.

\section{DAFTAR REFERENSI}

ANRI. (1981). Laporan-Laporan tentang gerakan Protes di Jawa pada Abad XX. Jakarta: Arsip Nasional Republik Indonesia.

Anonim, (2012). dalam http://library.binus.ac.id, diakses tanggal 15 Januari 2019 Pukul 13:00 WIB. 
Anshoriy, HM. N. (2010). Matahari Pembaharuan: Rekam Jejak KH. Abmad Dablan. Jakarta: PT. Niaga Swadaya.

Blackburn, S. (2007). Kongres Perempuan Pertama: Tinjauan Ulang. Jakarta: Yayasan Obor Indonesia.

Burhanudin, J. Fathurahman, O. (2004). Tentang Perempuan Islam : Wacana dan Gerakan. (Jakarta: Gramedia Pustaka Utama.

Hanafi, H. Abid Al Jabiri, M. (Penj). Bukhory,U. (2015). Dialog Timur dan Barat. Yogyakarta: IRCiSoD.

Ida, H. (2018). Feminisme Indonesia dalam Lintasan Sejarah, (Temali: Jurnal Pembangunan Sosial.

Jones, P. B. Boutillier, S. (2016). Pengantar teori-teori Sosial. Jakarta: Yayasan Pustaka Obor Indonesia.

Kartodirjo, S. (1982). Pemikiran dan Perkembangan Historiografi Indonesia. Jakarta: PT. Gramedia.

Kuntowijoyo. (2003). Metodologi Sejarah. Yogyakarta: Tiara Wacana.

Lapian, A.B. (2011). Indonesia Dalam Arus Sejarab: Masa Pergerakan Kebangsaan. Jakarta: Ichtiar Baru Van Hoeve.

Setiadi, E. (2011). Pengantar Sosiologi; Pemahaman Fakta dan Gejala Permasalahan Sosial: Teori, Aplikasi dan Pemecahannya. Jakarta: Kencana.

Noer, D. (1980). Gerakan Modern Islam di Indonesia 1900-1942. Jakarta: LP3ES.

Oey-Gardiner, M. (1996). Perempuan Indonesia: Dulu dan Kini. Jakarta: PT Gramedia Pustaka Utama.

Sculte Nordholt, H. Purwanto, B. Saptari, R. (2013). Perspektif Baru Penulisan Sejarah Indonesia. Jakarta: Yayasan Pustaka Obor Indonesia.

Stuers, C. (Perj). Rosa, E. (2008). Sejarah Perempuan Indonesia: Gerakan dan Pencapaian. Depok: Komunitas Bambu.

Warman Adam, A. (2007). Seabad Kontroversi Sejarah. Yogyakarta: Ombak. 